\title{
Engaging complexity
}

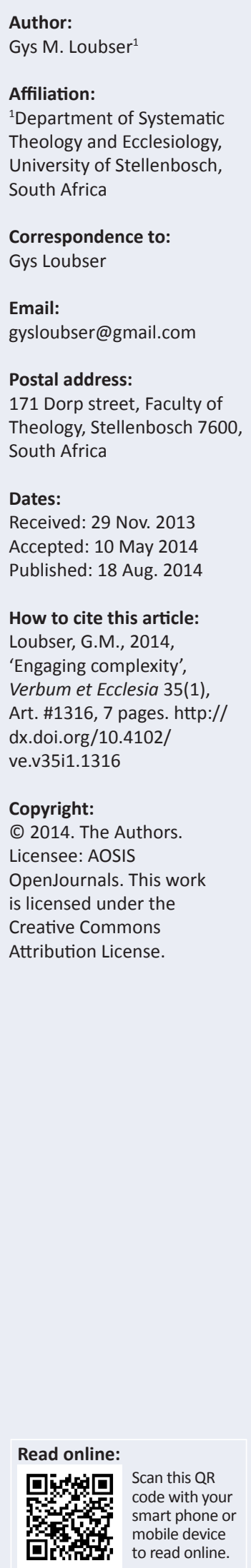

In this article, I discuss studies in complexity and its epistemological implications for systematic and practical theology. I argue that engagement with complexity does not necessarily assure a non-reductionist approach. However, if complexity is engaged transversally, it becomes possible to transcend reductionist approaches. Moreover, systematic and practical theologians can draw on complexity in developing new ways of understanding and, therefore, new ways of describing the focus, epistemic scope and heuristic structures of systematic and practical theology. Firstly, Edgar Morin draws a distinction between restricted and general complexity based on the epistemology drawn upon in studies in complexity. Moving away from foundationalist approaches to epistemology, Morin argues for a paradigm of systems. Secondly, I discuss Kees van Kooten Niekerk's distinction between epistemology, methodology and ontology in studies in complexity and offer an example of a theological argument that draws on complexity. Thirdly, I argue for the importance of transversality in engaging complexity by drawing on the work of Wentzel van Huyssteen and Paul Cilliers. In conclusion, I argue that theologians have to be conscious of the epistemic foundations of each study in complexity, and these studies illuminate the heart of Reformed theology.

Intradisciplinary and/or interdisciplinary implications: Therefore, this article has both intradisciplinary and interdisciplinary implications. When theologians engage studies in complexity, the epistemological roots of these studies need to be considered seeing that researchers in complexity draw on different epistemologies. Drawing on transversality would enhance such considerations. Furthermore, Edgar Morin's and Paul Cilliers' approach to complexity will inform practical and theoretical considerations in church polity and unity.

\section{Introduction}

During the last two decades, there has been a growing interest in the theory of complexity and its implications for how we understand an engage reality. A wide variety of researchers from diverse fields engage complexity studies, making complexity studies valuable in facilitating trans and interdisciplinary research. However, whilst studies in complexity are valuable in facilitating trans and interdisciplinary research, there are some difficulties regarding the way in which researchers within different disciplines draw on complexity. This is partly due to the absence of a theory of complexity. There is no unified theory of complexity that is embedded in a single epistemology, and this leads to the variety of ways in which researchers draw on complexity. By drawing on the work of Edgar Morin, Paul Cilliers, Wentzel van Huyssteen, Kees van Kooten Niekerk and Hans Buhl, I argue that even though there is no single theory of complexity, one can make a distinction between the different ways in which researchers draw on complexity with regard to foundationalist and non-foundationalist epistemologies.

\section{Restricted and general complexity}

As stated above, there is no single theory of complexity. ${ }^{1}$ Edgar Morin, however, argues that one can make a distinction between restricted and general approaches to complexity. To understand this distinction, it is necessary to look at the development of studies in complexity.

Kees van Kooten Niekerk and Hans Buhl trace the origin of the sciences of complexity ${ }^{2}$ back to the non-reductionist approaches of the 1930s (Van Kooten Niekerk \& Buhl 2004:4). In the 1930s, Ludwig von Bertalanffy introduced the term systems theory in opposition to reductionist descriptions of biological phenomena. This opposition to reductive descriptions is still

1.Chu, Strand and Fjelland (2003:20) explains that, although 'the early successes of complexity research have indeed invoked a widespread belief into the viability of a Theory of Complexity, today many prominent proponents of the science of complexity seem to have reduced their expectations and also doubt the absolute need of a Theory of Complexity. Their point of view seems to be that the science of complexity can still be productive even if it does not possess a rigorous overarching theory'.

2. Here I use the phrase sciences of complexity which should be distinguished from the phrase complexity studies. This distinction will become clear in the distinction between restricted complexity and general complexity. The phrase the sciences of complexity is used within restricted complexity, and complexity studies is used in general complexity. 
one of the main driving forces in complexity studies. Another important aspect of complexity studies, namely self-organisation, became prominent with the work of Ilya Prigogine who succeeded in describing dissipative systems mathematically by using nonlinear differential equations (Van Kooten Niekerk \& Buhl 2004:4). This meant that small changes in a system may have a large effect on the system. In the 1960s, Edward Lorenz used nonlinear differential equations to simulate weather patterns, and his research initiated the mathematical investigation of chaos, or chaos theory (Van Kooten Niekerk \& Buhl 2004:5). According to Kees van Kooten Niekerk and Hans Buhl, a hallmark of the sciences of complexity is its use of computer modelling to simulate and understand complex systems. As such, the development of the sciences of complexity is closely related to the development of the computer. They refer to the work of John Conway on cellular automata, Per Bak's research of self-organised criticality and Stuart Kauffman's use of computer simulations in investigating the origin and evolution of life (Van Kooten Niekerk \& Buhl 2004:5-8). What is important here is that the sciences of complexity originated from, and developed within, diverse research projects and not from a single theory of complexity. ${ }^{3}$ Furthermore, one of the driving forces behind the study of complexity is its non-reductionist argument. It is exactly here where the work of Edgar Morin and Paul Cilliers sheds light on complexity studies. Morin (1992) writes:

In contrast with the idea of a general theory of systems (or even a theory specific to systems), I wish ... to propose the idea of a systems paradigm capable of informing all theories, whatever their field of application or the phenomena in question. (p. 371)

Morin (1992:372) makes this suggestion because 'holism arises from the same simplifying principle as the reductionism to which it is opposed'. Morin argues that holism or a focus on the whole is a simplification or reduction to the whole. When researchers focus on the macro-unity of the system and ignore the parts or the micro, they are still busy with a reductive activity. In Morin's view, complexity studies have to be able to describe a complex system by holding the micro and macro together because the parts have a double identity - one that is individual and one that is common (Morin 1992:373). In other words, the characteristics of the parts and their interaction with each other are just as important as the system that develops from the interaction of the parts. Complexity cannot be simplified, and we need to unite ideas which seem mutually exclusive in the framework of reduction (Morin 1992:381). Morin (1992) writes:

We begin to catch a glimpse of a new form of rationality. The old rationality was content to fish for order in the sea of nature. But it caught no fish - only fish bones! By allowing us to conceive of organization and existence, the new rationality allows us to perceive not only the fish, but the ocean as well - that is to say, that which can never be caught. (p. 383)

It is Morin's desire to break with reductionist activity all together. This leads him to make a distinction between restricted complexity and general complexity. He argues that

3.Important to note is that systems theory also drew upon a number of different theories, including information theory and cybernetics (Van Kooten Niekerk \& Buhl 2004:4). classical science draws on three fundamental explanatory principles: (1) the principle of universal determinism which allows prediction, (2) the principle of reduction which allows simplification and (3) the principle of disjunction which allows isolating and separating knowledge and disciplines (Morin 2007:5). ${ }^{4}$ The epistemology and principles of classical science is still active when researchers are searching for the laws of complexity (Morin 2007:10). A system is simplified to sets of laws and universal truths which operate as the foundation of the sciences of complexity (Human \& Cilliers 2013:31). This is what Morin calls restricted complexity, and it is usually 'those approaches to complexity which developed from chaos theory and fractal mathematics' (Cilliers 2008:42). Researchers err when they think that they can find a method in complexity that can be applied automatically to the world (Morin 2007:28). Cilliers (2008) writes:

The problem is, however, severely compounded when the methods of the natural sciences are imposed upon, or, even worse, embraced in a simplistic way by the social sciences and humanities. The impression is then created that a traditional understanding of truth, which is problematic even in natural science, should form the criterion for proper work in social science. (p. 53)

In disagreement with the epistemology and principles of classical science, researchers in general complexity draw on different principles:

- a principle that conceives a relation between order, disorder and organisation where order does not only mean laws but also stability and regularities, and disorder also means collisions and irregularities

- a principle that conceives the relation of whole-part implication

- a principle that maintains the distinction but that tries to establish the relation (Morin 2007:10-11). ${ }^{5}$

Researchers in general complexity draw on an epistemology that rethinks the epistemology of classical science (Cilliers 2008:42). Human and Cilliers (2013:32) explain that '... general complexity point towards an epistemology of complex systems which examines the relationships between the parts as well as the parts themselves'. Preiser (2010:66) underscores this when she explains that the art of complexity thinking does not lie in describing opposites but in thinking both. One should not describe one thing in terms of the other but rather how the one is dependent on and determined by the other.

\footnotetext{
4.Robert Delorme explains that Morin argues against the separating of disciplines in classical science. Delorme (2010:246-247) explains that classical science 'generated a paradigm of simplification which has had great success but which also had mutilating consequences through excluding from scientific enquiry the features that could not be grasped by the paradigm and through setting rigid barriers between disciplines. Morin searches for a strategy of knowledge that would enable one to grasp or to create an articulation between sciences'.

5.Wentzel van Huyssteen's postfoundationalist epistemology links well with Morin's general complexity. Van Huyssteen argues for a postfoundationalist approach as a viable third option beyond foundationalism and nonfoundationalism. Van Huyssteen (1999:113) explains that a postfoundationalist approach 'should free us to approach our cross-disciplinary conversation with our strong beliefs and even prejudices intact, and while acknowledging these strong commitments, to identify at the same time the shared resources of human rationality in different modes of reflection ... a truly postfoundational move beyond objectivism and relativism is to rediscover the embeddedness of our rational reflection in the context of living evolving and developing traditions'.
} 
Researchers in general complexity recognise that it is necessary to reduce and constrain but understand that these reductions are provisional and subject to the observer (Human \& Cilliers 2013:32). To gain knowledge from a complex system, the system has to be modelled, and the model represents an interpretation of the system which will always be reductive (Cilliers 2007:83). Explaining this statement, Cilliers draws a distinction between knowledge and information. He explains that knowledge should be reserved for information that is situated historically and contextually by a knowing subject (Cilliers 2007:85). However, for knowledge to exist, we have to place limits on the information, which means that the complexity of a system needs to be reduced or interpreted in order to gain an understanding of it (Cilliers 2007:86). Thus, it is necessary to identify the boundaries of the system (Cilliers 2007:86), but these boundaries are simultaneously a function of the activity of the system and a product of the descriptive strategy (Cilliers 2008:47). We have to make certain modelling choices when describing phenomena because we cannot have complete knowledge of complex things (Woermann \& Cilliers 2012:404). We have to interpret, and our interpretation is developed in terms of the aims of our description (Cilliers 2000:46). However, the choice of models is not arbitrary because some models work better than others, but we cannot claim that this choice is an objective one (Osberg, Biesta \& Cilliers 2008:218). Models are necessary but always involve decisions and values.

\section{Epistemology, methodology, ontology and complexity}

In their book, Kees van Kooten Niekerk and Hans Buhl (2004) distinguish between the epistemological, methodological and ontological aspects of the study of complexity that have an impact on theological research. When we describe a system in terms of complexity, are we only describing our understanding of the system in terms of complexity, or is the system itself really complex (Van Kooten Niekerk \& Buhl 2004:11)? The distinction between epistemological and ontological complexity is very important because it has a far-reaching impact on the status of our knowledge. This distinction is of the utmost importance when theologians draw on complexity. Complexity studies also have methodological significance for understanding systems because it illuminates the way in which researchers interact with the system that is being studied and offers a variety of ways in which a system can be modelled (Van Kooten Niekerk \& Buhl 2004:11). It is exactly the methodological implications and applications of complexity that have made it so interesting and useful in trans and interdisciplinary research. The appropriateness of these different uses is still a point of discussion, but the methodological implications of complexity have been applied in numerous fields. Many theologians, however, focus on the epistemological and ontological implications of complexity and do not take note of the significance of the methodological implications of complexity.

\section{Theologians drawing on complexity}

By recognising that the purpose for an argument shapes the argument itself and by identifying whether the theologian is developing an epistemological, methodological or ontological argument, it is possible to offer a description of the way in which theologians draw on complexity in their research.

One of the earliest contributions to theological discourse on complexity is the edited volume Chaos and complexity: Scientific perspectives on divine action (Russel, Murphy \& Peacocke 1995). In this volume, the authors discuss a variety of themes linked with theological discourse on complexity. They discuss chaos, divine action, reductionism, emergence, downward causation, boundary conditions, self-organisation, thermodynamics, God, trinity, language, God-world relation, Trinitarian approaches, systems theory, top-down causation, quantum theory, causal gaps and bottom-up causation. The volume as a whole covers the epistemological, methodological and ontological aspects of complexity. However, important to note is that this volume grew out of a conference at Vatican City, and the editors (Russel et al. 1995) describe the purpose of the conference as follows:

The purpose of the conference was to explore the implications of chaos and complexity in physical, chemical, and biological systems for philosophical and theological issues surrounding the topic of divine action. (p. 1)

The link between chaos and complexity and the intent to explore the implications of complexity in the natural sciences for use in the humanities indicate that some of these discussions are dealing with restricted complexity.

Gregersen discusses two ways in which theologians can draw insight from the sciences of complexity. The first is focused on how the science of complexity may affect religious self-understanding, and the second is how theologians may appropriate insight from the sciences of complexity in theological terms (Gregersen 2004:153). Gregersen (2004:153-154) mentions some of the fruitful areas of contact between theology and the sciences of complexity:

- The worldview of the sciences is shifting from the world as a mechanical clock to a cluster of networks. This opens new avenues of conversation between theology and the science.

- The idea of self-organisation gives priority to the theological idea of continuous creation.

- Divine action does not need to contradict natural laws because there are no pre-ordained laws to break.

- Instead of focusing on individual genes in NeoDarwinism, the importance of interconnected living organisms is accentuated, which is closer to ethical and religious sentiments.

However, Gregersen's (2004:143) description of complexity is still shaped by restricted complexity because he explains 
that the '... aim of complexity research is to uncover the simple rules that generate the complex patterns of behaviour of natural phenomena. Simplicity often underlies complexity'. It is exactly these simple rules that are used in computer modelling ${ }^{6}$ and whilst computer modelling has been useful in some cases, by its nature, computer modelling is a very reductive activity.

Approaching complexity differently, there are theologians who draw on epistemologies and rationalities that are similar to what Morin has phrased a paradigm of systems (or a paradigm of complexity). ${ }^{7}$ In his article, Günter (2004:173) draws on complexity, epistemologically and methodologically, and argues that different theologies could be understood as different reductions or models of a multi-referential endeavour. By describing different theologies as different models, it is possible to identify models of theology that are reductive. Here one may identify certain feministic, liberation, African and biblical theologies that reduce theology to a simple underlying principle or critic. Some of these theologies offer a reductionist description of theology because they offer a description that is shaped by only one aspect of the system.

The work of Welker also finds its epistemology and rationality in what Morin calls the paradigm of complexity. Welker (1994:26) explains that human beings find it difficult to tolerate social complexity. We are constantly looking for a connecting link that is common to all. Therefore we use phrases such as 'the' human person and 'the' threat to humanity. Welker (1994) writes:

With the minimum of theological instinct, theologies and church leaders have, on the basis of a simplistic understanding of 'unity' (e.g., monohierarchical unity), condemned pluralism as if it were a unitary phenomenon. In so doing they have demonstrated an absence of the power to distinguish between individually disintegrative pluralism and the life-enhancing, invigorating pluralism of the Spirit. (p. 27)

His critique against simplification and his insistence on the necessity of plurality shows that he is working in general complexity. This approach can also be seen in other areas of his work. In reflecting on anthropology, Welker (2012:38) argues that both the macro-anthropological and micro-anthropological approaches are crucial for a circumspect analysis. We have to reflect on the whole as well as the parts. The work of Dirk Smit is also embedded in general complexity. In a series of articles written in the 1980s, Smit discusses different ways in which spirituality can be modelled (Smit 1989:88-92). However, he makes it clear that not one of these models is sufficient on its own. We

6.Gregersen (2000:60) writes: "Complex phenomena such as life and social systems cannot be handled with a step-by-step causal analysis; these systems are much too large ... for a precise explanation in terms of its constitutive components. What we can do however is make more simplistic computer simulations of the complex realities ..'Morin and Cilliers admit that we need to reduce the system in order to realities .... Morin and Cilliers admit that we need to reduce the system in order to understand it, but this reductive activity should not be seen as the aim of the study of complexity. This is why Morin suggests a paradigm of complexity with a rationality

7.Kuhn, Woog and Salner (2011:263) also emphasize this approach when they explain that they '... seek to go beyond focusing on complexity per se, to using complexity as a heuristic device for developing cognitive agility'. need to keep all these different models in mind when dealing with spirituality (Smit 1989:92). The question now becomes how researchers can keep different models together whilst reflecting on the whole and the parts. I propose that the work of Paul Cilliers and Wentzel van Huyssteen can illuminate such an approach.

\section{Complexity, interdisciplinarity and transversality}

Instead of searching for simple and universal underlying principles or laws in complex systems, Cilliers argues that it is better to deal with each system on its own terms. Therefore, he (Cilliers 2008:45-46) offers 12 characteristics that might be found in complex systems. ${ }^{8}$ Complex systems are open systems that are constituted by a large variety of parts that interacted with each other in a dynamic and nonlinear way. These characteristics of complex systems are generated within complexity studies, but complexity studies is not a discipline with a focus, experiential scope and heuristic structures. Complexity studies could be described as an interdisciplinary conversation regarding the transversal issue of complexity. As such, the characteristics of complex systems offered by Cilliers are gained within a transversal conversation. These characteristics can then be included in the focus, experiential scope and heuristic structures of a particular discipline as are appropriate. ${ }^{9}$ However, one cannot describe the complexity of a biological system in the same way as one would describe the complexity of mental systems. Such epistemic shortcuts would imply a foundationalist epistemology. John Mingers (2008) puts it as follows:

Because systems thinking can be applied across the disciplines it has often been the case that systems ideas have been applied to a particular domain by people who are not themselves expert in that area. The result of this is often weak and superficial, and contributes to a poor reputation for systems. It is much better when people who are already expert in their own discipline use systems concepts to develop their own ideas. (p. 257)

In his book, Cilliers (1998) draws on the characteristics of complex systems generated within a transversal space when he proposes that postmodern society can be understood in terms of complexity. He does not apply or use the same approach to complexity as used in biology or economics. Cilliers appropriates the characteristics of complex systems for philosophy with the intent of describing postmodern society in terms of complexity. By including these appropriated characteristics of complexity to the focus, experiential scope and heuristic structures of philosophy, Cilliers illuminates the complexity of postmodern society within the context of philosophy, thereby safeguarding

8.Chu et al. (2003:26-27) propose a similar approach when they use the phrase generators of complexity. They explain that .... the very existence of complex systems science shows that the over-simplification that we find in physics is of broad application, but by no means of universal application ... to approximate the world as not contextual and nearly closed works in many cases, but not always world as not contextual and nearly closed works in many cases, but not always .... They propose that radical openness and contextuality are two of the generators of complexity (Chu et al. 2003:28). In order to break with the search for the laws of complexity, they propose that we should '... focus more on properties of complex
systems, rather than the details of mechanism' (Chu et al. 2003:29).

9.Van Huyssteen (2006:75) explains that transversality makes it possible to discuss a transversal issue as well as to draw on criteria of different disciplines. However, this happens within the transversal space. 
the integrity of philosophy. Even though Cilliers does not explicitly describe this exercise as transversal, in terms of Van Huyssteen's description of transversality, Cilliers does incorporate the characteristics of complexity in philosophy transversally.

Wentzel van Huyssteen explains that, through transversality, one acknowledges that, whilst disciplines are connected and intertwined in many ways, they do have their own integrity and identities. A transversal approach makes it possible to acknowledge the point of contact between disciplines without these disciplines merging into one (Van Huyssteen 2006:23). By applying the concept of transversality to his description of interdisciplinary facilitation, Van Huyssteen argues that a transversal approach makes it possible to move from one discourse to another whilst acknowledging contextuality. ${ }^{10}$ A transversal approach is a fusion of epistemology and hermeneutics (Van Huyssteen 2006:22). ${ }^{11}$

In Figure 1, each cylinder represents a discipline, and viewed from the top, it looks as if the cylinders intersect. In Figure 2, we view the cylinders from the side and see that they do not intersect, but they all move though the transversal point. The illustration in Figure 2 shows that these disciplines do not intersect each other directly but explain different layers of a transversal issue due to the difference in their experiential scopes. ${ }^{12}$

It is important that the boundaries between disciplines are not blurred, because Van Huyssteen argues against the assimilation of different disciplines (Van Huyssteen 2006:19). Through a transversal approach, one does not intend to create a new multi-focused discipline. The intent of a transversal approach is to explore the point of contact between disciplines without compromising the integrity of the disciplines involved. Transversality makes it possible for scholars to discuss the shared point and then return to their respective disciplines. This lends itself to an appropriate and contextual incorporation of the insight generated within interdisciplinary research within the specific discipline. Researchers reflect on a transversal point from their discipline's specific focus, experiential scope and heuristic structures. The intent of

10.Montuori (2013:216) writes: 'It is not surprising that Bateson, Jantsch, Maruyama and Morin have all drawn extensively from General Systems Theory (GST) and Cybernetics. Both GST and Cybernetics emerged as attempts to develop a "transversal" language, a way of thinking that could move across disciplines and re-connect what had been torn asunder in disciplinary fragmentation." Montuori (2013:217) explains that transversal approaches stress the importance of context and the dangers of decontextualisation. It is exactly the danger of the decontextualisation of knowledge in complexity studies that is the focus of the
present article.

11.Schrag (1992:149) writes: '... certain tendencies in the employment of the vocabulary of transversality need to be resisted. Chief among these tendencies is the rationalistic impulse to sublate the several usages in the various disciplines into a higher concept that totalizes the different faculties of knowledge into a seamless unity viewed from above, as well as the positivistic impulse to determine a usage that is somehow paradigmatic and normative for all the rest, inviting a hegemonic unity of the sciences seen from below.

12. Osmer (2008:172), a Princeton colleague of Van Huyssteen, distinguishes between correlational, transformational and transversal models of cross-disciplinary dialogue and comments: Unlike the transformational approach, the transversal model presupposes a more fluid and dynamic understanding of the relationship between disciplines. Disciplines are not pictured as distinct language games but as networks that transverse one another and share the common resources of rationality. While this model has much in common with the correlation approach, it gives greater attention to the pluralism found in virtually every field today. In light of this pluralism, cross-disciplinary dialogue must become more concrete than is typically the case in correlation models.'

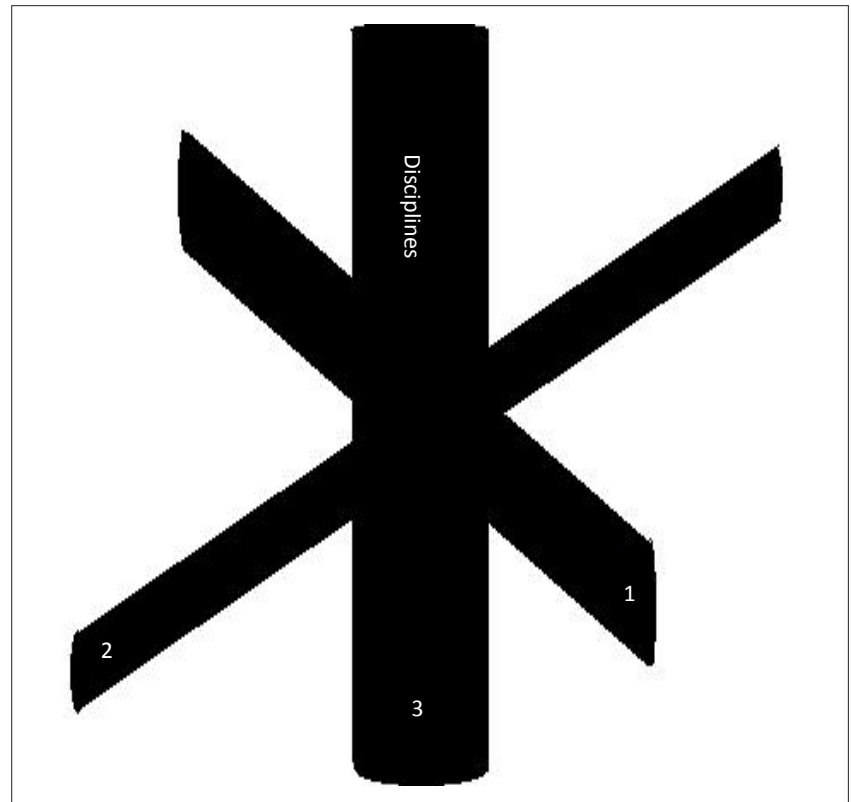

Source: Author's own construction

FIGURE 1: Disciplines crossing viewed from above.

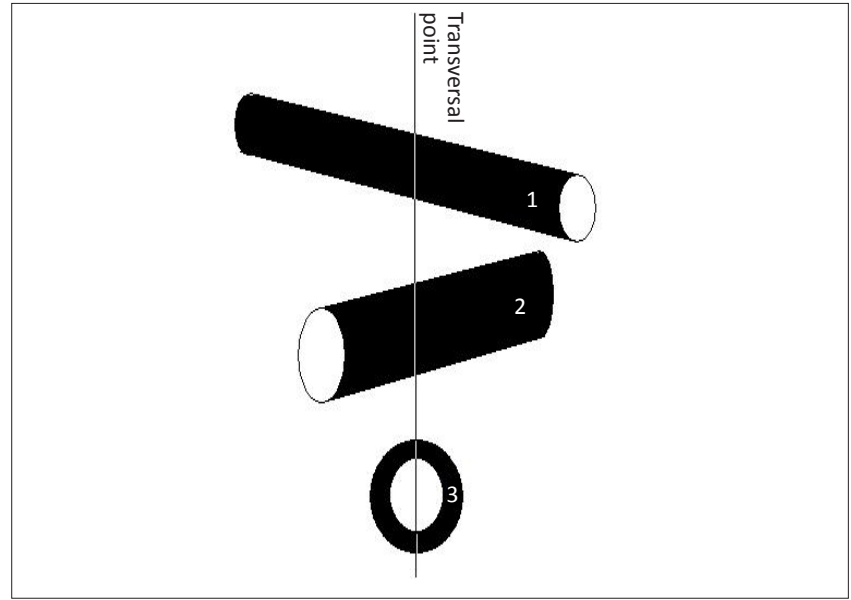

Source: Author's own construction

FIGURE 2: Disciplines crossing transversal point viewed from the side.

such a reflection is to unpack the different layers of each discipline's knowledge of the transversal point and discuss the points of association and disassociation. However, the purpose of such a conversation is not to reach a consensus but to illuminate the different layers of a transversal point. The insights gained within this transversal conversation can then be taken back into each participating discipline and included as is appropriate for its focus, experiential scope and heuristic structures.

Additionally, through a transversal approach, one guards against scholars taking epistemic shortcuts (Van Huyssteen 1998:78). Epistemic shortcuts can be seen in many interdisciplinary encounters. The concept refers to an uncritical insertion of knowledge from one discipline to another. This can be seen when the insights of biologists on the complexity of biological systems are directly applied to social systems (cf. Van Huyssteen 1998:44-45). This means that, although social systems can be understood in terms 
of complexity, we need to acknowledge that the working of a social system is different to that of an amoeba. Cilliers (2008:53) explains that the social scientists and scholars in the humanities cannot proceed in the same way as the natural scientists do. ${ }^{13}$ Scholars from different disciplines are encouraged to develop models that would generate understanding of that which they mean to understand. These models may be different, but the knowledge generated in these disciplines can then be brought into interdisciplinary reflection transversally (Van Huyssteen 1999:136). ${ }^{14}$ Materia and Baglio (2005) illuminate the impact of complexity studies on the health sciences in their short editorial 'Health, science and complexity'. They explain that researchers in genetic epidemiology have realised that they underestimate the effect of environment and overestimated the effect of gene (Materia \& Baglio 2005:534). They have also started to re-evaluate their models and taken into account the importance of context. Moreover, researchers in epidemiology no longer consider randomised controlled trails as the highest standard for all types of clinical questions because one universal study design is not necessarily suitable for all research objectives. Most interestingly, these researchers argue that qualitative research should be integrated into systematic reviews. Clearly, complexity has had an impact on epidemiology. What do these changes in epidemiology mean for research in theology? These changes have all been epistemological changes, which make it much easier to appropriate in theological research. The recognition of context is important. Theology is never developed in a cultural vacuum and therefore theologians have to recognise the influence of context on beliefs, faith and faith communities. This might entail re-evaluating our models of ethics, pastoral care, anthropology and God. Here, we might think of the atheistic movement as a critic of outdated models and a search for new ways in which to practice faith. However, whilst the epistemological changes in epidemiology can be appropriated for theological reflection, theology is a different system with a different history and different challenges. Therefore, theologians are encouraged to re-evaluate their epistemologies and develop theologies in ways that are appropriate for their context, but what these changes and re-evaluations might entail cannot be determined by another discipline or system.

\section{Conclusion}

Theologians, along with a wide variety of researchers from other fields, have drawn on complexity in many ways, and as such, the study of complexity has become a natural and widely influenced facilitator of interdisciplinarity. Morin's distinction between restricted complexity and general complexity assists us in illuminating reductive uses of complexity in these fields of research. He suggests that

13.Cilliers (2008:54) adds that social scientists and scholars in the humanities do not need to proceed in the same way as natural scientists do because general complexity argues against the superiority of the within the foundationalist epistemology of restricted complexity.

14.Van Huyssteen (2008:518) explains: 'Transversal reasoning ... is a pragmatic approach to the performative praxis of reason as we venture down the risky road of interdisciplinary dialogue. As such, it is not about arbitrarily opening ourselves up or closing ourselves off to other viewpoints. It is about discovering what it might mean to share an epistemic space that allows for the kind of interdisciplinary critical evaluation that includes a critical self-evaluation and optimal understanding.' complexity also informs our epistemology and proposes a paradigm of complexity. In this paradigm, we should describe rationality itself differently, and acknowledging the knower in the process of inquiry changes the way we describe rationality. Montuori (2008) puts it eloquently:

With Morin we find the knower taking center stage and becoming a subject of inquiry, self-reflection and self-analysis. This opens up an entirely different understanding of the nature of inquiry, deepening the complexity and forcing the inquirer to take responsibility for his or her own process. Not unlike the process of training required for psychoanalysts, Morinian inquiry involves a recognition that all inquiry is engaged by a human being, not an objective lens with no emotions, stressors, political and social constraints, and so on. Inquiry therefore requires a process of self-inquiry. ${ }^{15}$ (pp. $\left.x x x i x-x l\right)$

Cilliers explains that, whilst there are no simple laws to complexity, there are characteristics of complexity that makes it possible for us to identify a system as complex and describe it according to its own constraints. Van Huyssteen explains that these characteristics could be appropriated in different research projects transversally, which will safeguard the integrity of each research field involved and open up new research avenues. It is through the work of these scholars that theologians can orientate themselves within this interdisciplinary conversation and draw on complexity. When theologians engage complexity in this way, we can generate knowledge from within theological research rather than importing knowledge from elsewhere.

For example, Osberg et al. (2008:218-219) explain that '... the only reason rules work in models is because models have well defined boundaries'. This is interesting when we should think of dogma as the rules and a specific theology as the model. The Dutch Reformed Church (DRC) draws on a reformed model of theology and its rules or dogmas. During the last few years, there have been many discussions regarding homosexual clergy and the acceptance of the Belhar Confession. These two discussions are examples of two completely different discussions if we were to describe the Dutch Reformed Church as a complex system. The discussion regarding homosexual clergy is about rules of the system. These rules work very well when the boundaries of the church are well defined. However, when the boundaries of the church are open, less defined and allow for interaction with its environment, which it definitely does, these rules might become too reductionist. The church leaders should therefore recognise that their discussions regarding homosexual clergy are partly a modelling problem. Dogma can only be strictly adhered to in a closed model of church and society.

15.The inquirer is also very important in Van Huyssteen's postfoundationalist approach. Van Huyssteen (1999:152) explains that, '... as human beings, we are characterized by self-awareness, and our individual, personal motivations or reasons for believing, acting, and choosing are not only closely tied in with some sense of who this I is, but are indeed epistemically shaping the value judgments we make in terms of this self-conception'. Furthermore, Van Huyssteen (1999:144) proposes that '... learning to make the right or appropriate decisions, or solve certain problems, therefore involves the development of intellectual skills that are in many problems, therefore involves the development of intellectual skills that are in many ways, analogous to physical skills. Cilliers underscores this idea when he argues that ethics should be understood as something that constitutes our knowledge and us. Welker (1994:24) is also aware of the influence of his self-conception in his research when he explains that he .... must examine carefully the extent to which these boundaries influence and mark not only myself as a concrete individual, but also my general view and statements about "the individual," "the person," the good, the rational, the timely, indeed even what is "willed by God"'. 
The acceptance of the Belhar Confession involves a reevaluation of the current model of theology on which the DRC draws. The Belhar Confession offers an interpretation of faith that would inevitably change the DRC's model of theology. The question that is paramount for the DRC is whether or not the model of theology that they currently use is sufficient for the extremely complex society in which they practise their faith? Does the Belhar Confession help in developing a more appropriate model of theology for reformed Christians in South Africa? This is the same question that was asked of previous and already accepted confessions. All confessions offer an interpretation of faith within a specific context that assists in developing a model of theology. The work of the theologian is to continuously ask whether the model of theology upon which it draws is adequate for engaging the reality of faith. Osberg et al. (2008:224) explains that '... the system is never in a state where it is fully actualised, is never fully "present" at any point in time, because an integral part of it is that which is not part of it'. In this way, studies in complexity is not only a rich resource for theologians, but more than this, it illuminates the heart of Reformed theology.

\section{Acknowledgements \\ Competing interests}

The author declares that he has no financial or personal relationship(s) that may have inappropriately influenced him in writing this article.

\section{References}

Chu, D., Strand, R. \& Fjelland, R., 2003, 'Theories of complexity: Common denominators of complex systems', Wiley Periodical 8(3), 19-30.

Cilliers, P., 1998, Complexity and postmodernism: Understanding complex systems, Routledge, London.

Cilliers, P., 2000, 'Rules and complex systems', Emergence 2(3), 40-50. http://dx.doi org/10.1207/S15327000EM0203_04

Cilliers, P., 2007, 'Why we cannot know complex things completely', in F. Capra, A. Juarrero, P. Sotologo \& J. van Uden (eds.), Reframing complexity: Perspectives from the north and south, pp. 81-90, ISCE Publishing, Mansfield. (Exploring Complexity Book Series, vol. 1).

Cilliers, P., 2008, 'Complexity theory as a general framework for sustainability science', in M. Burns \& A. Weaver (eds.), Exploring sustainable science: A South African perspective, pp. 39-57, African Sun Media, Stellenbosch.

Delorme, R., 2010, Deep complexity and the social sciences: Experience, modelling and operationality, Edward Elgar, Cheltenham. http://dx.doi. org/10.4337/9781781000663

Du Toit, C., 2000, Research Institute for Theology and Religion, University of South Africa, Pretoria.

Gregersen, N., 2000, 'Theology and the science of self-organised complexity', in $\mathrm{C}$. Du Toit (ed.), Evolution and creativity: A new dialogue between faith and knowledge, pp. 57-91, Research Institute for Theology and Religion, University of South Africa, Pretoria.
Gregersen, N., 2004 'Complexity: What is at stake for religious reflection?', in K. van Kooten Niekerk \& H. Buhl (eds.), The significance of complexity: Approaching a complex world through science, theology and the humanities, pp. 135-165, Ashgate Publishing Limited, Aldershot.

Günter, T., 2004, 'Complexity in systematic theology: The case for the Christian concept of "new creation" in the dialogue with science', in K. van Kooten Niekerk \& H. Buhl (eds.), The significance of complexity: Approaching a complex world $\& \mathrm{H}$. Buhl (eds.), The significance of complexity: Approaching a complex world
through science, theology and the humanities, pp. 167-193, Ashgate Publishing through science, the

Human, O. \& Cilliers, P., 2013, 'Towards an economy of complexity: Derrida, Morin and Bataille', Theory, Culture \& Society 30(5), 24-44. http://dx.doi. org/10.1177/0263276413484070

Kuhn, L., Woog, R. \& Salner, M., 2011, 'Utilising complexity for epistemological development', World Futures: The Journal of Global Education 67(4/5), 253-265.

Materia, E. \& Baglio, G., 2005, 'Health, science, and complexity', Journal of Epidemiology and Community Health 59(7), 534-535. http://dx.doi.org/10.1136/ jech.2004.030619

Mingers, J., 2008, Realising systems thinking: Knowledge and action in management science, Springer Science and Business Media, Inc., New York.

Montuori, A., 2008, 'Foreword: Transdisciplinarity', in B. Nicolescu (ed.), Transdisciplinarity: Theory and practice, $\mathrm{pp}$. ix-xvii, Hampton Press, Inc., Cresskill.

Montuori, A., 2013, 'Complexity and transdisciplinarity: Reflections on theory and practice', World Futures 69, 200-230.

Morin, E., 1992, 'From the concept of system to the paradigm of complexity', Journal of Social and Evolutionary Systems 15(4), 371-385. http://dx.doi.org/10.1016/10617361(92)90024-8

Morin, E., 2007, 'Restricted complexity, general complexity', in G. Gershenson, D. Aerts $\&$ B. Edmonds (eds.), Worldviews, science and us: Philosophy and complexity, pp. 5-29, World Scientific Publishing, London.

Osberg, D., Biesta, G. \& Cilliers, P., 2008, 'From representation to emergence: Complexity's challenge to the epistemology of schooling', Educational Philosophy and Theory 44(1), 213-227. http://dx.doi.org/10.1111/j.1469-5812.2007.00407.x

Osmer, R.R., 2008, Practical theology: An introduction, Eerdmans, Grand Rapids.

Preiser, R., 2010, 'Observing representational practices in art and anthropology: A transdisciplinary approach', The Journal for Transdisciplinary Research in Southern Africa 6(1), 57-72.

Russell, C.R.J., Murphy, N. \& Peacocke, A., 1995, Chaos and complexity: Scientific perspectives on divine action, Vatican Observatory Publications \& Berkeley: The Center for Theology and the Natural Sciences, Vatican City State.

Smit, D.J., 1989, 'Kan spiritualiteit beskryf word?', Nederduits Gereformeerde Teologiese Tydskrif 30(1), 83-94.

Schrag, C.O., 1992, The resources of rationality: A response to the postmodern challenge, Indiana University Press, Bloomington.

Van Huyssteen, J.W., 1998, Duet or duel? Theology and science in a postmodern world, SCM Press, London.

Van Huyssteen, J.W., 1999, The shaping of rationality: Toward interdisciplinarity in theology and science, Eerdmans, Grand Rapids.

Van Huyssteen, J.W., 2006, Alone in the world?: Human uniqueness in science and theology, Eerdmans, Grand Rapids.

Van Huyssteen, J.W., 2008, 'Primates, hominids, and humans - from species specificity to human uniqueness? A response to Barbara J. King, Gregory R. Peterson, Wesley J. Wildman, and Nancy R. Howell', Zygon 43(2), 505-526. http://dx.doi. org/10.1111/j.1467-9744.2008.00931.x

Van Kooten Niekerk, K. \& Buhl, H. (eds.), 2004, The significance of complexity: Approaching a complex world through science, theology and the humanities, Ashgate Publishing Limited, Aldershot.

Welker, M., 1994, God the Spirit, transl. J.F. Hoffmeyer, Fortress Press, Minneapolis.

Welker, M., 2012, The theology and science dialogue: What can theology contribute, Neukirchener Verlagsgesellscharft mbH, Neukirchen-Vluyn.

Woermann, M. \& Cilliers, P., 2012, 'The ethics of complexity and the complexity of ethics', South African Journal of Philosophy 31(2), 403-419. 